\title{
Towards a better understanding of management development in South Africa
}

\author{
P. Human ${ }^{\star}$ and Linda Human \\ Graduate School of Business, University of Cape Town, Private Bag, Rondebosch, 7700 Republic of South Africa
}

Received 12 September 1988; accepted 11 November 1988

\begin{abstract}
In this article, an attempt is made to provide a better understanding of management development in South Africa by the development of a theoretical framework within which the process of management development can be situated. It is argued that management development can be understood by using a framework of domination, which provides a useful conceptual model within which the basic dynamics of management development can be placed. This framework describes the structural positioning of the principal actors, the relationship between them, and the possible world-views which may arise from these positions. The problem of management development in South Africa is discussed in terms of this framework and practical solutions elicited.
\end{abstract}

In hierdie artikel word 'n teoretiese raamwerk vir bestuursontwikkeling in Suid-Afrika voorgestel. 'n Beter begrip van bestuursontwikkeling kan moontlik verkry word deur die begrip van dominansie teoreties sentraal te plaas. Die raamwerk beskryf die strukturele posisies van die primêre akteurs, die relasies tussen hulle en die moontlike wêreldbeskouinge wat verbandhoudend is met verskillende posisies. Die probleme van bestuursontwikkeling in Suid-Afrika word bespreek in terme van die teoretiese raamwerk en praktiese oplossings word voorgestel.

* To whom correspondence should be addressed

\section{Introduction}

Management, as a distinct occupational group with specific tasks to perform and specific responsibilities to meet, is becoming an increasingly important force in the current and future development of South African society. The successful development of this society would appear to be dependent to a high degree upon the effectiveness and efficiency of organizations in relation to the production and distribution of goods and services; and as the organization can be viewed as a developmental instrument which is directed and controlled by management, its effectiveness and efficiency would appear to be largely a function of the quality of management. This assertion holds true for all organizations - be they private, public, profit-making, non-profitmaking, large or small. Indeed, this argument could be extended to include the importance of management not only to the ensuring of the effectiveness andiefficiency of the organization but also to the creation of a better society. The development of professional management can consequently be seen as more than a crucially important strategic objective of South African organizations; the development of professional managers must also be seen in the broader context of the society at large. As Harbison (1973:3) argues: ‘... human resources - not capital nor income, nor material resources - constitute the ultimate basis for the wealth of nations... Clearly, a country which is unable to develop the skills and knowledge of its people and to utilize them effectively in the national economy will be unable to develop anything else'.

In order for the skills and knowledge of their employees to be utilized optimally, organizations will have to manage their human resources far more professionally than they are today. Indeed, it could be argued that many of the proponents of the need for black manager development make one important and generally wrong assumption: that is, that white management is already adequately doing its job. It will be argued below that management development requires far more than the promotion of employees into managerial positions; the re-orientation, training and development of those managers we already have, is an urgent pre-requisite to the development of those with managerial potential.

In this paper, a general orientation to management development in South Africa is proposed. The point of departure is that management development, as it is currently practised, is problematic not only because it is insufficient but also and probably more importantly because it is based on shallow and infirm theoretical foundations. It is argued that management development should initially be understood in its sociological context rather than as a purely technical issue. Following on from this, we hope to show how management development efforts can be more effectively directed. More specifically, it is argued that the problem of management development should be understood by using a framework built around the concept of domination. Domination constitutes a pervasive characteristic of South African society, and its nature is such that the ground rules of social and organizational mobility are highly biased and inequitable. It is also the case that these ground rules are perceived as illegitimate by probably the majority of the population, with current attempts at restructuring such rules also being in grave danger of falling foul of the perceptions of the majority. The problem is that those who find themselves in advantageous positions in the social hierarchy frequently perceive the traditional rules as legitimate, such beliefs leading to an inaccurate assessment of management 
development problems and hence a misdirected effort in their solution.

In this paper, we attempt to provide a better understanding of the problems surrounding management development and to suggest certain solutions emanating from our theoretical orientation.

\section{A model of domination}

That the few govern the many would appear to constitute a 'social fact' evidenced in all societies and most organizations or collectivities of people throughout the world. All social collectivities which, by implication, pursue a single, or a variety of, collective goals tend to develop a core of members which takes charge of the overall responsibility for the coordination of individual tasks and for the strategic direction of the collectivity. Social and organizational life are characterized by a division of labour, the most fundamental being the division between those who make the important decisions on behalf of the whole and those with limited discretion. A distinction can thus be made between those who dominate and have power over others and those who are subordinate and have little power over others. Although this kind of distinction is conceptually pleasing, we know, empirically, that organizational life is neither that simple nor that neat. However, for the sake of the argument that follows, we will retain this generalized conception for the time being.

It is in the interest (which may be defined as opportunities, privileges, rewards and status currently experienced or expected in the future) of the dominant few to retain and even extend their position of dominance $v i s-\grave{a}$-vis the dominated. The maintainance of their interests involves the protection of the boundaries between themselves and those who may threaten such interests. This process is called social closure. 'By social closure Weber means the process by which social collectivities seek to maximise rewards by restricting access to resources and opportunities to a limited circle of eligibles' (Parkin, 1979: 44). Domination can thus be described as a process whereby one group consistently and successfully monopolizes advantages by closing off opportunities to the subordinate group below them. The criteria for exclusion may include any social characteristic, inter alia, race, sex, language, religion, education, social status, and geographical region of origin.

The boundary, or to use Parkin's (1979) term, the 'structural fault' running through the society or the organization in question, and which divides the dominant and dominated groups, together with the processes involved in both the maintenance of, and challenges to, this boundary are central to our understanding of domination and mobility.

Two reciprocal forms of social closure exist. The first occurs through a process of exclusion. Exclusion constitutes the exercise of power from above and is a process whereby opportunities are closed off by imposition. This process inevitably engenders the potential for a converse process, which involves usurpation by those groups which are excluded. Usurpation acts in an upwards direction and constitutes a process whereby the excluded groups attempt to obtain some of the advantages and opportunities of the powerful (Parkin, 1979:44-45). The excluded groups attempt to capture some or all of the advantages of the powerful group through various means and in extreme cases by the process of revolution.

The structural fault in society or the organization can be seen as the line or fissure where the directional flow of power changes; the orientation from above is topdown and that from below is bottom-up. This line divides the social collectivity into two major classes, the one based on the principles of exclusion and the other on the principles of usurpation. This fissure represents, moreover, the source of most ideological differences inasmuch as the different structural positions tend to determine, or to coincide with, diverse ideologies or world views. A number of distinguishing characteristics of the different ideologies are conceptually identified in Table 1.

\section{Table 1 Characteristics of the different ideologies}

\begin{tabular}{|c|c|c|}
\hline & Dominant groups & Subordinate groups \\
\hline Power position & Powerful & Powerless \\
\hline Exercise of power & Downwards & Upwards \\
\hline Goals & To maintain & To capture \\
\hline Interests & Mostly material & Mostly ideal \\
\hline Power base & $\begin{array}{l}\text { Ownership of the } \\
\text { means of life chances }\end{array}$ & Other people \\
\hline Time frame & Short term & Long term \\
\hline Social pressure & High & Low \\
\hline Social orientation & Individualist & Collectivist \\
\hline
\end{tabular}

The dominant groups' power resides in their ability to own or control life chances, in the form of inter alia, opportunities (for education or occupational positions), privileges and capital. The primary or most immediate goal of these groups is to maintain their privileged position. Such privileges are, moreover, generally of a material rather than an ideal nature and include money, life-styles and structural positions. This does not mean that the powerful are idealess; rather, this means that the central emphasis of their existence is material to the extent that their privileged position is based upon the retention of ownership and control. The process of usurpation also constantly reminds those higher up that their position is fickle, the elite often being forced into fire-fighting activities to offset the challenge from below. This leads us to the notion that the orientation of the powerful is generally reactive. In South Africa since 1976, the black community has taken most of the initiative (in the form of strikes, riots, and boycotts) and the white community has been forced to respond (with labour and other reforms, commissions of enquiry, the establishment of the Urban Foundation, etc). This kind 
of reactive stance also means that the time frame of those in power is often relatively short term; they are under pressure and react to current challenges rather than working in terms of a vision of the future. A worldview which may develop from within dominant groups may thus be described as elitist, top-down, reactive, materialistic, and fragmented.

By way of contrast, the subordinate groups often have little power apart from their numbers; they often have relatively few material interests (and therefore little to lose); they often have expectations relating to power being in their hands in the future; they are also often less pressurized in terms of achieving their goals. The longer term, idealistic and collectivist bent of the subordinate groups has many advantages, not least of which is the relative ease with which collective action can be mobilized and the time and energy, fuelled by ideals, which they have at their disposal. This does not necessarily imply that their position is preferable to that of the privileged group. Indeed, those in power will consistently attempt to suppress usurpation practices by coercion or by psychological manipulation.

This model constitutes a useful conceptual framework within which the basic dynamics of domination and mobility can be understood. It both describes the structural positioning of the principle actors, the relationship between them, and the possible world-views which may arise from these positions. In refining this very generalized model, the following considerations need to be taken into account:

1. Some groups in society find themselves in a marginal position between the clearly dominant and the clearly subordinate. A case in point is the South African white 'working class' who may make use of both exclusion (to keep blacks out) as well as usurpation (to gain access to the privileges of those higher up). Other examples include closed-shop unions, black consciousness movements, and feminists. Exclusion may be viewed in these instances as a short-term tactic (to ensure collective action) with a view to achieving long-term strategic success in their usurpation practices.

2. The diverse ideologies which are held to arise from differing structural positions are not necessarily generalizable to all members of the specific groups. It is an oversimplification to argue that symmetry between structural position and ideology exists. Both across and within classes, people may share some beliefs and differ with respect to others. However, as we are concerned primarily in this paper with what divides people and with what inhibits mobility, we will concentrate on within-group similarities and betweengroup differences. Such similarities and differences are, moreover, both real and fundamental to our understanding of the process of mobility.

3. The criteria for exclusion require further elaboration. Parkin (1979) argues that such criteria can be broadly classified as collective criteria (that is, social characteristics such as class, race, sex, and caste) and individual criteria (that is, property and credentials). Collective criteria are well geared to transmit advantages from one generation to the next, whereas individual criteria are rather less stable over time and more geared towards the protection of current advantages. The modernization process is generally associated with secularization which tends to shift criteria of exclusion from the collective to the individual. This, some people wrongly assume, implies that the foundations of closure will be eliminated. However, although the positional structure may become more flexible and less stable, the process of closure is only modified. The few still govern the many at the expense of the many and, although the rules change, imbalances in the process of social mobility prevail. A good example, here, is provided by social mobility in Britain. Although direct discrimination against women, blacks, and the working-class may have decreased, such discrimination still persists but in a different form. Factors relating to social class such as patronage, nepotism, and inheritance (collective criteria) may have been replaced by individual criteria (such as credentials or education) but the ability to provide a good education is still greater amongst those who hold powerful positions. In other words, 'As society tries to become "fairer", with equal pay legislation and the like, new "unfairnesses" may arise as the dominant groups try to find new ways of perpetuating their position. Direct discrimination in the labour market may decline but competition for schooling and credentials may intensify' (Heath, 1981: 191). It could be argued, that the powerful are in the best position to win this battle, even though the lower classes may have more opportunities than they had before.

4. This brings us to a very important point. Since exclusion is inevitable and perhaps even a necessity (consider the case of specialization in the organization), and since exclusion from all means of life rarely exists in an enduring form (Murphy, 1986:25), the question 'when does closure become problematic' becomes relevant. Closure becomes problematic when the criteria for closure are not accepted by the majority of the population. When closure and its criteria are perceived as illegitimate, severe conflict can shake the society (Murphy; 1986:27). The degree to which closure is problematic in a given social collectivity is directly proportional to the extent to which the members of that collectivity deem the rules of exclusion as illegitimate. Legitimacy is a matter of belief or conviction; it involves people judging rules or practices as morally 'right' and complying with these rules or practices out of a sense of 'duty' or moral respect. Legitimacy arises from within the individual and cannot be imposed or expected from without.

\section{The legitimacy crisis in South Africa.}

'South Africa practises the textbook case of legal violations of legitimacy by denying the majority population equal political rights' (Adam \& Moodley, 1986:129). Both the policy of Apartheid and all that it entails are rejected by the majority of the population. 
Illegitimacy may be viewed as the norm. Although those in power view the rules of domination (principally based on race and ethnicity) as legitimate, and although those in power attempt to legitimize these rules through the legal framework, this system is rejected by the majority of South Africans. As perceptions of legitimacy are limited to members of the dominant groups, and as the subordinate groups do not comply out of a sense of belief in the system, order is maintained primarily through a process of coercion. Put simply, compliance is based on fear.

Compliance to unjust laws and acquiescence with unequal life chances in both the organization and society at large are made possible by co-ercion and dependency; often subordinate groups are oppressed to the extent that usurpation practices become too costly (in terms of loss of job, income, housing, etc.)

The absence of legitimacy with respect to the criteria of exclusion results in a fragile and highly explosive social system. Indeed, a central problem in South Africa concerns different perceptions with respect to these criteria; the dominant groups generally regard these criteria as legitimate whilst the subordinate groups reject them. The 'de-racialization' of society and of most large corporations is in essence an attempt to remove the most visible barriers to mobility across the 'structural fault'. A critical question which has to be asked, however, is whether the removal of one, albeit important, criterion, fundamentally changes the structure of domination or whether it merely serves to modify the basis of domination. In other words, does the removal of this one criterion imply the shift from collective to individual criteria of exclusion without changing the fundamentals of domination? Put in another way, is the removal of the 'petty apartheid' apparatus enough or does this merely 'modernize racial domination'? (See Adam, 1971).

The criteria of exclusion are a systematic complex of manifest (formal, legal and noted) criteria and latent (underlying beliefs, hidden perceptions and stereotypes) principles. In other words, criteria of exclusion have their foundation in the overall belief system or paradigm of the dominant group.

If we are seriously interested in management development, which in itself is problematic given the context of domination, it is important to investigate the basic assumptions underlying the paradigms of the main actors; in other words, the values of both the powerful and the powerless.

\section{Paradigms}

Thomas Kuhn employed the concept 'paradigm' to describe '...the entire constellation of beliefs, values, techniques, and so on shared by members of a given community' (Camhis, 1979:60). Paradigms are best understood as world views or action frameworks which are coherent, internally logical and structured. It is generally assumed that underlying assumptions and values will inform and be related to attitudes and perceptions which, in turn, will inform and be related to behaviour.
Social actors create the paradigm in terms of which they live. A paradigm '... comes into being as individuals take action, interpret that action, and share with others their interpretations. These interpretations, or "typifications" are attempts to classify the behaviour into categories that will enable the actors to respond to it in similar fashion' (Scott, 1987:495). The process of reciprocal typification is a long-term process whereby certain forms of action come to be associated with certain classes of actors. For example, the dominant groups give orders and the subordinate group complies. The acceptance of typifications is called institutionalization. 'Institutionalization occurs whenever there is a reciprocal typification of habitualized actions by types of actors' (Berger \& Luckmann, 1967:54). Once institutionalization occurs a paradigm is formed and acquires an objective existence independent of particular actors. The assumptions of the paradigm are 'taken for granted' as '.... the "way things are" and/or the "way things are to be done" (Scott, 1987:496).

Paradigms are accepted by their users as valid and natural and their content is rarely questioned. Kuhn (1970:5) argues that during times of relative social stability, people work under the assumption that their paradigm is correct. He suggests, moreover, that 'A paradigm can insulate the community from those socially important problems that are not reducible to puzzle form, because they cannot be stated in terms of the conceptual and instrumental tools the paradigm supplies' (Kuhn, 1970:37).

When the context changes, and the inappropriateness of the paradigm becomes too obvious to ignore, a paradigm shift should occur. In the absence of paradigm shift, the paradigm becomes an ineffectual burden. Such is the case with current management development strategies.

The first step in the search for a new and appropriate paradigm is the surfacing and evaluation of current taken-for-granted assumptions. We will take a look at these assumptions in the process of applying these theoretical insights to the process of management development in South Africa.

\section{Application}

The theory of social closure helps us to understand those social processes by means of which dominant groups, who have interests of their own to protect, exclude the dominated groups from competition, as well as those social processes by means of which the dominated attempt to usurp the advantages of the powerful. It has been argued that collective criteria (such as race, sex, and religion) have been made anachronistic by the process of industrialization and that, in most modern societies, these criteria have been replaced by the individual criteria of credentials and property. In South Africa, and in most South African organizations, however, a tension still exists between collective and individual criteria, this tension being exacerbated by the values of those in charge. As the rules of exclusion are 
based on the values of the powerful, and as values tend to reflect themselves in the attitudes and behaviour of the dominant group, it would appear, contrary to the public statements of many large corporations, that, on the values level, these corporations are neither able nor willing at present to develop non-racial cultures or to provide management development with the impetus it requires. The research of Human (1988) suggests that the paradigms of most white South African managers are such as to place a low priority on management development. Moreover, the research of Human (1988) and Human \& Hofmeyr (1987) also indicates an antipathy to the development of blacks. More specifically, this research suggests that, whilst professing to accept equal opportunity and affirmative action in the organizations in which they work, the majority of white South African managers still doubt the inherent capabilities of blacks. The paradigms of these managers appear to be incoherent in the sense that what they say they believe in (equal opportunities; a non-racial workforce) and what they actually believe in (blacks are inherently inferior) are two different things. Alternatively, the failure of management development, and specifically black manager development programmes in many organizations could be ascribed to the fact that lip-service is paid to these activities, whilst managers continue to manage in terms of a competing paradigm. It would appear, moreover, that the dominant paradigm - the 'rational actor' paradigm which favours individualism, conservatism, autocracy, unitarism, and rationalism - is amenable neither to management development nor the advancement of blacks into managerial positions (Human, 1988).

It would appear that, for management development activities to be successful, a paradigm shift has to take place amongst the majority of white managers; in other words that these managers have to be 'converted' to a social consciousness orientation. It would also appear that these managers have to be trained in people management, experience suggesting that such skills are sadly lacking in most organizations. Thus, if management development involves creating and developing managers who can manage others for the more effective and efficient utilization of resources, organizations have a two-fold challenge to confront: they not only have to train and develop people from disadvantaged groups and move them up into managerial positions, but also - and perhaps more importantly - organizations must examine the values and develop the people management skills of those managers they already have. Thus, management development requires far more than merely moving generally black people through the structural fault; as much attention needs to be paid to those who will manage them once they are there. In other words the paradigms or the values and assumptions of managers have to be changed prior to the provision of people management skills.

The problems of management development are many and complex and include problems relating to the structural aspects of society as well as the particular issues faced by black managers on their arrival in higher level positions.

One of the major problems relating to the structural aspects of society concerns the processes of social mobility mentioned earlier. Because of the historical development of the South African society, whites tend to occupy managerial and professional positions and blacks the lower level, semi-skilled and unskilled posts. Movement through the structural fault in society is exacerbated by the processes of social mobility which, in the majority of countries of Western Europe and even the USA, assign better opportunities and life chances to those males born to fathers in elite positions. Put simply, the higher the position of the father on the occupational ladder, the greater the chances that his son will reach a similar position himself (Heath, 1981). Boys born to fathers at the top of the job structure stand a better chance than those born to lower level fathers of obtaining meaningful work. Thus, although direct discrimination against blacks may have declined somewhat and may continue to decline in the future, the dominant groups will continue to perpetuate their position through the provision of quality education for their children. In other words, even if race becomes a less relevant criterion for exclusion in the future, the dominant white group will still try to find new ways of perpetuating domination. It is likely that, with a movement from collective to individual criteria of exclusion, competition for educational qualifications will become more acute. Even though, if this situation were to materialize, black people may well have better opportunities than before, whites would remain in a powerful position to retain their advantages in this regard.

Arguments relating to social mobility link into another set of arguments relating to the role of legislation, environment and education in the provision of life chances. Historically, in South Africa, both legislation and the provision of education have been geared towards keeping black people in a dominated position below the structural fault. Similarly, the kinds of environment in which black children have had to grow up are often far inferior to the kinds of housing, facilities and amenities available to whites. All of these factors have impacted and still impact on the ability of black people to move into management positions. Such factors are related, moreover, to a conservative ideology, an ideology which is still pervasive amongst many of those whites in senior positions in the organisations in which black people are being developed.

The black manager working in an environment which is dominated by whites is thus in an unenviable position. Indeed, the research of Human \& Icely (1987); Human \& Hofmeyr (1987) and Human (1988), suggests that the attitudes of whites towards black management development are generally negative and that a great deal of subtle and not so subtle discrimination exists. As stated earlier, these kinds of attitudes relate back to the values of these managers, their paradigm being responsive neither to black management development in particular nor management development in general. 
Other problems experienced by black managers in essentially white organizations include problems relating to culture, education and their marginal position. To begin with the latter, black managers find themselves caught between the two competing ideologies of exclusion and usurpation. In other words, they are caught between the conflicting pressures of black resistance to exclusion and attempts by whites to react to this resistance. Black managers are often not accepted by whites and are frequently perceived as 'sell-outs' by blacks, their ambiguous or schizophrenic position being exacerbated by the separation of the domestic and social worlds of blacks and whites.

Black managers thus find themselves faced with competing loyalties and responsibilities; put simply, they often do not know whose side they should be on. Research suggests that the underperformance of some black managers may result from this marginal position rather than from an inability to do the job (Human, 1981, Human \& Hofmeyr, 1985).

Other problems faced by black managers include problems relating to culture and a lack of educational qualifications. Although both of these arguments are important, they should not be overstated. Both of these arguments could well exacerbate contentions of illegitimacy, inasmuch as both could be perceived increasingly as a proxy for collective criteria on the grounds of race. In other words, a central challenge for most organizations is the reassessment of minimum entry criteria for specific jobs as well as a reorientation towards the concept of 'merit'. If the minimum educational qualifications required for certain jobs are too high or if the organization in question takes a limited and apparently dubious approach to the assessment of potential or ability - and in some instances this would indeed appear to be the case - then black people could assume that they are excluded from jobs they feel able to do. Exclusion, in turn, could be perceived as related to race with what are perceived as unrealistically high educational qualifications or inappropriate assessments of merit being construed as merely an excuse to keep black people out. Similarly, arguments relating to differences between African and western culture should also be handled with care. Again, many black managers, who feel that few really important differences between themselves and their white counterparts exist in terms of ability to get the job done, reject arguments to the effect that their culture leaves them at a disadvantage in the business world. Although these black managers would not want to argue away cultural differences, they would question the relevance of cultural arguments to performance. Again there exists a danger that the cultural argument is employed as a proxy for the collective criterion of race. What appears to be required is a model which would allow us to assess individuals as individuals and in terms of which individual strengths and weaknesses and the effects of individual problems in relation to culture, education and marginality could be assessed by both the subordinate and his manager in a spirit of trust and co-operation. In the absence of this kind of model, the potential for the increasing illegitimacy of the rules of exclusion in terms of both collective and individual criteria remains acute. And without rules of exclusion which are perceived as legitimate by the majority of employees in the organization, an extremely unstable and unmanageable situation will develop.

\section{Management development practice}

An analysis of management development in terms of the insights mentioned above helps us both to better understand the problems of management development as well as what needs to be done about them. With respect to management development practice, the following points are of note:

Management development is a strategic issue which should be recognized by top-management during the strategic planning process. It is not an issue which should be consigned to the personnel department but, rather, its importance should be recognized at the strategic level and weighed up against other strategic decisions. The personnel department has a role to play in the coordination of training and development but should not be held responsible for driving the decision to accept the reorientation of values and training in people management skills as a key strategic thrust. The responsibility for this thrust should lie with top management and the line function. This determination of priorities at strategic level provides a clear indication of the importance of the role of management development in the company. Without top management commitment to management development, little is likely to happen. Thereafter, top management commitment to training and development as well as its commitment to other strategic objectives should be filtered down the organization. Such commitment should, moreover, include a commitment to the reorientation and training in people management skills of current managers and the inclusion of the management of subordinates in the key objectives of each manager. Unless managers are assessed, in terms of their own performance, on the extent to which they have coached their subordinates, other key objectives are going to take priority.

It has already been stated that the paradigms of the majority of white managers militate against management development in general and the management development of blacks in particular. Value surfacing exercises can be employed to expose these values and an attempt can be made to create an appropriate set of values to ensure management development. In this way, some kind of synthesis between the more broadly based ideologies of exclusion and usurpation can be achieved in an attempt to both reduce differences between managers and managed and to alter the value structures of managers. Such attempts at value change can be reinforced by top management commitment, by regular monitoring of progress and by making line managers accountable for the progress of their subordinates. Value change is, moreover, critical to the legitimacy of individual criteria of exclusion. 
It is during the strategic planning stage that decisions with regard to affirmative action should be made. These decisions should be based on a strengths, weaknesses, opportunities and threats analysis of the company as well as both a short and long-term evaluation of the broader environment and an analysis of company values. Proposed affirmative action activities should be fed into the manpower planning process and selection and recruitment methods.

Manpower planning, as part of the strategic process, provides us with the opportunity to determine current and future manpower requirements. This in turn links into the succession planning process which provides us with the opportunity to develop individuals with potential for future positions. Succession planning, in turn, links into the process of professional people management. People management, as the joint responsibility of the manager and subordinate, involves a process whereby key tasks and measurable performance standards are determined, (current, and in terms of the succession plan, future) training needs are identified, training, development and coaching takes place, and performance feedback/appraisal and career planning are undertaken. Professional people management is a critical aspect of the development of people of all races.

This process treats individuals as individuals and provides a logical structure in terms of which individual training needs can be identified. Coaching, training and development should, moreover, be geared to individual needs and career plans.

People management provides a process by means of which organizations can move away from an emphasis on race towards an individual assessment of strengths and weaknesses as determined through a process of negotiation between manager and subordinate.

It is, however, with the processes of selection and recruitment that the real move from collective criteria of exclusion to individual criteria of exclusion has to take place in a meaningful way. At present, many organizations confuse educational qualifications with standards and assume that if the educational requirements attached to specific jobs are lowered, then standards will also drop. This is not necessarily the case, however, as standards may also drop if the educational level is too high and people are bored with what they are doing or if other job-related criteria are more important than education. Also, if through inadequate definition and understanding of the job at hand, we attach educational criteria which are too high to the job, we unfairly exclude disadvantaged groups from competition. In our search for the right person for the job, two important facts should be borne in mind. Firstly, the skills shortage is going to deteriorate and secondly, there are a large number of disadvantaged people who have the ability or the potential to perform management jobs but who have not obtained the educational qualifications they would have had, had historical circumstances been different. In view of these facts, together with the problems surrounding the use of psychometric tests, advertisements and all-white selection panels, the central challenge which currently confronts organizations which wish to develop a nonracial management team is the development of fairer methods of selection which select for either the potential or the ability to do the particular clearly defined job at hand in a way which allows us to adequately assess the potential or the ability of all applicants irrespective of background. Unless we are able to develop these techniques and unless we are able to reorientate ourselves with respect to the concept of merit, where such reorientation does not involve a lowering of standards, the passage from collective (race) to individual (credentials) criteria of exclusion is not going to be a smooth one, particularly in view of persistent glaring inequities in the educational system. As long as race is linked to education and selection is (dubiously) linked to education (instead of more relevant selection criteria) and hence race, the legitimacy of even individual criteria for exclusion remains problematic.

\section{Conclusion}

In this article, an attempt has been made to provide a better understanding of management development in South Africa by the development of a theoretical framework within which the process of management development can be situated. It has been argued that the problem of management development should be understood by using a framework of domination, which provides a useful conceptual framework within which the basic dynamics of management development can be understood. This framework has been employed to understand the structural positioning of the principle actors, the relationship between them, and the worldviews which may arise from these positions. It has been argued that management development should be understood within this framework and reformulated accordingly. Such a reformulation would involve management development being regarded as a strategic issue and as involving the reorientation and training of white managers in order to facilitate the upward movement of blacks. It has also been predicted that severe consequences would ensue from a decision not to reorientate ourselves to current criteria of exclusion.

\section{References}

Adam, H. 1971. Modernizing Racial Domination. Berkeley: University of California Press.

Adam, H. \& Moodley, K. 1986. South Africa without Apartheid. Cape Town: Maskew Miller and Longman.

Berger, P. \& Luckmann, T. 1967. The Social Construction of Reality. New York: Doubleday.

Camhis, M. 1979. Planning Theory and Philosophy. London: Tavistock.

Harbison, F. 1973. Human Resources as the Wealth of Nations. New York: Oxford University Press.

Heath, A. 1981. Social Mobility. Glasgow: Fontana.

Human, L. 1981. Some tentative comments on the Black

Manager in a White World. S.Afr. J. Bus. Mgmt., vol.12, 103-108. 
Human, L. \& Hofmeyr, K. 1985. Black Managers in South African Organisations. Cape Town: Juta.

Human, L. \& Icely, N. 1987. Trends in the Attitudes of White Workers to the Upward Occupational Mobility of Blacks: Findings from two companies. S. Afr. J. Labour Rel., vol.11, 4-23.

Human, P. 1988. Do Multi-Nationals Make a Difference? Paper presented at Multi-national Culture: Social Impacts of a Global Economy. New York, Hempstead, Hofstra University, March 1988.

Human, P. \& Hofmeyr, K. 1987. Attitudes of South African
Managers to the Advancement of Blacks in Business. $S$. Afr. J. Labour Rel., vol.11, 53-68.

Kuhn, T.S. 1970. The Structure of Scientific Revolutions. Chicago: University of Chicago Press.

Murphy, R. 1986. Weberian Closure Theory: A contribution to the ongoing assessment. Br. J. Soc., vol.37, part 1, 21-41.

Parkin, F. 1979. Marxism and Class Theory: A Bourgeois Critique. London: Tavistock.

Scott, W.R. 1987. The Adolescence of Institutional Theory. Admin. Sci. Quart., vol.32, 493-511. 